\title{
Prediction of asthma in symptomatic preschool children using exhaled nitric oxide, Rint and specific $\lg \mathrm{E}$
}

\author{
Daan Caudri, ${ }^{1}$ Alet H Wijga, ${ }^{2}$ Maarten 0 Hoekstra, ${ }^{3}$ Marjan Kerkhof, ${ }^{4}$ \\ Gerard H Koppelman, ${ }^{5}$ Bert Brunekreef, ${ }^{6,7}$ Henriette A Smit, ${ }^{2,7}$ Johan $\mathrm{C}$ de Jongste ${ }^{1}$
}

- Supplementary data and tables are published online only. To view these files please visit the journal online (http://thorax. bmj.com).

${ }^{1}$ Department of

Pediatrics/Respiratory Medicine, Erasmus University, Rotterdam, The Netherlands

${ }^{2}$ The Netherlands Centre for Prevention and Health Services Research, National Institute for Public Health and the

Environment (RIVM), Bilthoven, The Netherlands

${ }^{3}$ Centre for Paediatric

Allergology, University Medical Centre St Radbout, Nijmegen,

The Netherlands

${ }^{4}$ Department of Epidemiology,

University Medical Centre

Groningen, University of

Groningen, The Netherlands

${ }^{5}$ Beatrix Children's Hospital,

University Medical Centre

Groningen, University of

Groningen, The Netherlands

${ }^{6}$ Institute for Risk Assessment

Sciences, University Medical

Centre Utrecht, Utrecht, The

Netherlands

${ }^{7} J u l i u s$ Centre for Health

Sciences and Primary Care,

University Medical Centre

Utrecht, Utrecht, The

Netherlands

Correspondence to

Professor J C de Jongste,

Erasmus MC/Sophia Children's

Hospital, Department of

Paediatric Respiratory Medicine,

PO Box 2060, Rotterdam 3000

$\mathrm{CB}$, The Netherlands;

j.c.dejongste@erasmusmc.nl

Received 17 September 2009

Accepted 26 May 2010

\section{ABSTRACT}

Rationale For clinicians it remains very difficult to predict whether preschool children with symptoms suggestive of asthma will develop asthma in later childhood.

Objective To investigate whether measurement of fraction of exhaled nitric oxide $\left(\mathrm{FE}_{\mathrm{NO}}\right)$, interrupter resistance (Rint) or specific immunoglobulin E (lgE) in 4-year-old children with suggestive symptoms can predict asthma symptoms up to age 8 years.

Methods Children were recruited from the PIAMA birth cohort. All children with symptoms suggestive of asthma at age 3 or 4 years, who were invited for medical examination at age $4(n=848)$, were eligible.

Associations of $\mathrm{FE}_{\mathrm{NO}}(\mathrm{n}=308)$, Rint $(\mathrm{n}=482)$ and specific $\lg E(n=380)$ at 4 years with wheezing and asthma at the ages of 5-8 years were assessed using repeated measurement analyses. The added predictive value of these objective tests was then investigated by including parameters for clinical history in the model.

Results $\mathrm{FE}_{\mathrm{NO}}$ and specific lgE measured at 4 years were associated with wheezing and asthma at 8 years. Both tests also remained significant predictors after mutual adjustment and adjustment for clinical history: $\mathrm{OR}$ on wheezing at 8 years for $\mathrm{FE}_{\mathrm{NO}}\left({ }^{10} \mathrm{log}\right.$-scale, per IQR) 1.6 (95\% Cl 1.1 to 2.2) and for specific lgE 2.8 (95\% Cl 1.9 to 4.1). Rint was significantly associated with wheezing at age 6 , but not at 7 and 8 years.

Conclusions In preschool children with symptoms suggestive of asthma, both $\mathrm{FE}_{\mathrm{NO}}$ and specific $\lg \mathrm{E}$ measured at age 4 , but not Rint, improved the prediction of asthma symptoms until the age of 8 years, independent of clinical history.

\section{INTRODUCTION}

In preschool children, asthma-like symptoms such as wheezing and coughing are highly prevalent. ${ }^{1}$ Unfortunately, children with transient symptoms are not easily distinguished from those with persistent asthma on the basis of reported symptoms. Objective tests to support an asthma diagnosis include spirometry, to assess airway obstruction and reversibility; bronchoprovocation, to assess airway responsiveness; and sputum induction, to measure airway inflammation, a hallmark of asthma. ${ }^{2}$ These tests are difficult to perform in children under the age of 6 years since active cooperation is necessary. ${ }^{3}$ Non-invasive measurement of the fraction of exhaled nitric oxide $\left(\mathrm{FE}_{\mathrm{NO}}\right)$ has received much interest due its ability to reflect eosinophilic airway inflammation. ${ }^{4}{ }^{5}$ Several studies have shown elevated $\mathrm{FE}_{\mathrm{NO}}$ values in children with asthma or atopy. ${ }^{6-12}$ Moeller et al showed that $\mathrm{FE}_{\mathrm{NO}}$ could distinguish between the different phenotypes of preschool wheezers. ${ }^{13}$ However, prospective data on the prognostic value of $\mathrm{FE}_{\mathrm{NO}}$ in preschool children for later symptoms are scarce. In clinical practice, measurement of $\mathrm{FE}_{\mathrm{NO}}$ would only be worthwhile if it offers an added predictive value over information that is already available, such as a standard clinical history. This has not been investigated so far. Interrupter resistance (Rint) measurement can be easily performed in young children and correlates with asthma symptoms. ${ }^{14-16}$ Specific immunoglobulin E (IgE) to inhalant allergens in young children is associated with the risk of persistence of asthma symptoms. ${ }^{17-20}$

The aim of our study was to investigate prospectively whether $\mathrm{FE}_{\mathrm{NO}}$, Rint and/or specific $\mathrm{IgE}$ at the age of 4 years in children with respiratory symptoms could be used to predict asthma symptoms up to the age of 8 . We used data from the 'Prevention and Incidence of Asthma and Mite Allergy' (PIAMA) birth cohort. ${ }^{21}$ Children were eligible if they reported 'wheeze', 'shortness of breath' or 'nightly cough without a cold' at the age of 3 or 4 years. $\mathrm{FE}_{\mathrm{NO}}$, Rint and specific IgE were measured at the age of 4 years and children were followed until the age of 8 . The added value of the tests to predict asthma symptoms until the age of 8 was calculated.

\section{METHODS}

\section{Study population}

Recruitment of the PIAMA cohort took place in 1996-1997; 7862 pregnant women were invited to participate; 4146 women (53\%) agreed (1327 allergic and 2819 non-allergic, based on a validated screening questionnaire). ${ }^{22}$ Their children were followed up for 8 years, using questionnaires for parental completion, partly based on the International Study of Asthma and Allergies in Childhood (ISAAC) core questionnaires. ${ }^{23}$ At 4 years, all children with an allergic mother and a random sample of children with a non-allergic mother were invited for a medical examination, including measurement of $\mathrm{FE}_{\mathrm{NO}}$, Rint and specific IgE levels $(\mathrm{n}=1808)$. A detailed description of the study design has been published previously. ${ }^{21}$ The study protocol was approved by the medical ethics committees of the participating university hospitals. For the current study, we selected all children who were invited for the medical examination at 4 years and who reported at least one respiratory symptom 
suggestive of asthma (wheeze, shortness of breath, or cough at night without a cold) in the questionnaire at age 3 or 4 years $(\mathrm{n}=848)$ (figure 1).

\section{$\mathrm{FE}_{\mathrm{NO}}$, Rint and specific $\lg \mathrm{E}$ measurement}

$\mathrm{FE}_{\mathrm{NO}}$ at age 4 was measured offline according to European Respiratory Society (ERS)/American Thoracic Society (ATS) guidelines. ${ }^{24}$ For every child, duplicate exhaled air samples and an ambient air sample were collected in Mylar balloons, and analysed using a chemoluminescence analyser (Sievers NOA 280B, Boulder, Colorado, USA). FE NO $_{\text {was }}$ expressed in parts per billion (ppb). Rint was measured in $\mathrm{kPa} / \mathrm{l}$ with MicroRint (MicroMedical, Rochester, Kent, UK) during expiration, with occlusion of the airway at peak expiratory flow. Median values for at least five acceptable measurements were calculated. Detailed descriptions of both measurement techniques were previously published. ${ }^{8} 1625$ Sensitisation was defined as specific $\mathrm{IgE}$ of $\geq 0.70 \mathrm{IU} / \mathrm{ml}$ for at least one of six tested airborne allergens. To assess the added predictive value of these measurements over reported clinical history, three variables previously shown to have the highest predictive value on later symptoms were selected $^{26}$ : (1) allergic mother (yes/no); (2) doctor's diagnosis of eczema ever until age 4 (yes/no); and (3) wheezing frequency during the fourth year of life (no/1-3 times per year $/ \geq 4$ times per year). Mothers were considered 'allergic' if they reported any of the following items: asthma, hay fever, house dust allergy, house dust mite allergy or pet allergy.

\section{Outcomes}

Based on data from the annual questionnaires at age 5- 8 years the following dichotomous outcomes were defined, each pertaining to the past 12 months:

- Wheezing: at least one episode

- Inhaled steroid prescription by a medical doctor

- Doctor's diagnosis of asthma: a parental report of a doctor's diagnosis of asthma at any time AND a parental report of asthma symptoms during the past 12 months.

\section{Statistical analysis}

Univariate associations between $\mathrm{FE}_{\mathrm{NO}}$, Rint and specific $\operatorname{IgE}$ measurements and respiratory outcomes were investigated with logistic regression. $\mathrm{FE}_{\mathrm{NO}}$ values had a right-skewed distribution; a normal distribution was achieved after ${ }^{10} \mathrm{log}$-transformation. Generalised estimating equations were used to take into account the correlation between repeatedly measured outcomes in the same individual. Variables for clinical history were included in the model to examine additional predictive value of the tests over clinical history. The study design was stratified for allergy of the mother, and any interaction with this variable was investigated. After a complete case analysis, missing data were imputed multiple times to check for any bias that could result from complete case analysis. ${ }^{27} 28$ The 'Multivariate Imputation by Chained Equations' (MICE) procedure in the statistical program $R$ version 2.6.2 was used to create 10 imputed data sets $(\mathrm{n}=848) .{ }^{29}{ }^{30}$ Results were combined using PROC MIANALYZE in SAS 9.1 (SAS Institute, Carey, North Carolina, USA). Finally,
Figure 1 Flow chart of the study population. All 848 eligible children enter each of the three arms of the flowchart. *Respiratory symptoms were defined as a positive response to at least one of the following three questions: 'Has your child had wheezing or whistling in the chest in the last 12 months?' and/or 'Has your child had tightness of the chest or shortness of breath in the last 12 months?' and/or 'Has your child had a cough during the night, when he/she did not have a cold or a chest infection, in the last 12 months?' +Out of 306 children with available $\mathrm{FE}_{\mathrm{NO}}$ (fraction of exhaled nitric oxide), 51 used steroids at the age of 4 years; these children were not excluded from the analysis. $\ddagger$ The following six airborne allergens were tested for: house dust mite (Dermatophagoides pteronyssinus), cat, dog, grass pollen (Dactylis glomerata), birch and Alternaria alternata. IgE, immunoglobulin E; Rint, interrupter resistance.

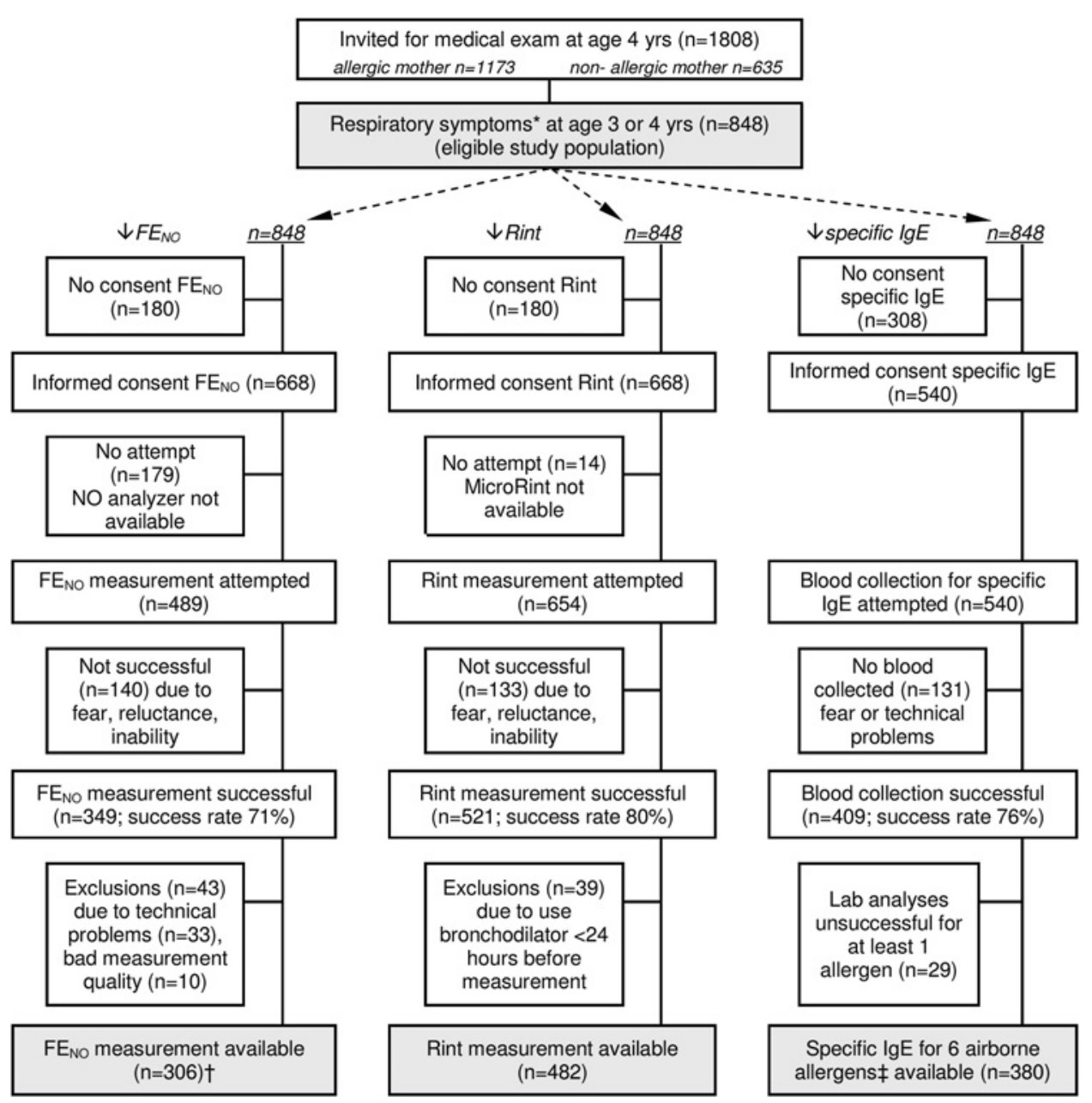


a model was built including clinical history, specific IgE and $\mathrm{FE}_{\mathrm{NO}}$, which allowed us to estimate the added predictive value of $\mathrm{FE}_{\mathrm{NO}}$ over the combination of clinical history and specific IgE. The online data supplement provides a detailed description of study design, analysis and the multiple imputation procedure (table E1).

\section{RESULTS}

\section{Study population}

At the age of 4 years 1808 children were invited for medical examination, of whom $848(46 \%)$ reported at least one of the following symptoms at 3 or 4 years: wheeze $(n=379)$, shortness of breath $(n=385)$ or nightly cough $(n=592)$. The eligible study population therefore consisted of 848 children. An acceptable $\mathrm{FE}_{\mathrm{NO}}$ measurement was obtained from 306, Rint from 482 and specific IgE from 380 children (figure 1). We compared children with and without available values for these measurements separately, with respect to baseline characteristics and symptoms at 8 years (table 1). Children with available $\mathrm{FE}_{\mathrm{NO}}$ values $(\mathrm{n}=306)$ were similar to children without $(\mathrm{n}=542)$, the only difference being the educational level of the mother. Children with Rint values ( $\mathrm{n}=482$ ) were also more likely to have a mother with higher education than children without Rint measured $(\mathrm{n}=366)$, and had significantly fewer symptoms at the age of 8 . Children with IgE data were more likely to be boys, to have an allergic mother, older siblings and to be exposed to cigarette smoke in utero, compared with children with missing IgE data. With respect to symptoms at baseline and at 8 years, there were no major differences. The distribution of clinical symptoms and objective tests that were used to predict later asthma symptoms is given in table 2 .

Table 1 General characteristics of the eligible study population

\begin{tabular}{|c|c|c|c|c|c|}
\hline \multirow[b]{2}{*}{ Baseline characteristics } & \multicolumn{2}{|c|}{$\begin{array}{l}\text { Eligible } \\
\text { study } \\
\text { population } \\
(\mathrm{N}=\mathbf{8 4 8})\end{array}$} & \multirow{2}{*}{$\begin{array}{l}\mathrm{FE}_{\mathrm{N0}} \\
(\mathrm{N}=306) \\
\%\end{array}$} & \multirow{2}{*}{$\begin{array}{l}\text { Rint } \\
(\mathrm{N}=482) \\
\%\end{array}$} & \multirow{2}{*}{$\begin{array}{l}\text { Specific } \\
\lg E \\
(N=380) \\
\%\end{array}$} \\
\hline & $\mathrm{n} / \mathrm{N}$ & $\%$ & & & \\
\hline Gender (female) & $391 / 848$ & 46 & 47 & 47 & $41^{* *}$ \\
\hline Allergic mother & $567 / 848$ & 67 & 66 & 66 & $72^{* *}$ \\
\hline Allergic father & $289 / 846$ & 34 & 35 & 35 & 35 \\
\hline \multicolumn{6}{|l|}{ Maternal education level } \\
\hline Low & 195/832 & 23 & 21 & 20 & 23 \\
\hline Middle & $366 / 832$ & 44 & 41 & 43 & 43 \\
\hline High & $271 / 832$ & 33 & $38^{*}$ & $36^{*}$ & 34 \\
\hline Caesarean section & $86 / 834$ & 10 & 10 & 11 & $7^{* *}$ \\
\hline Pets in the house (at birth) & $473 / 844$ & 56 & 54 & 55 & 54 \\
\hline Older sibling present & $422 / 846$ & 50 & 49 & 52 & $59^{* *}$ \\
\hline Smoking during pregnancy $\dagger$ & $147 / 831$ & 18 & 18 & 17 & $21^{*}$ \\
\hline Smoking in the house (at age 4 ) $\neq$ & $191 / 798$ & 24 & 26 & 23 & 24 \\
\hline \multicolumn{6}{|l|}{ Symptoms at baseline (age $3-4$ ) } \\
\hline Wheeze & $379 / 848$ & 45 & 47 & 45 & 48 \\
\hline Shortness of breath & $385 / 848$ & 45 & 48 & 46 & 47 \\
\hline Cough at night§ & $592 / 848$ & 70 & 73 & 70 & 69 \\
\hline \multicolumn{6}{|l|}{ Symptoms at age 8 years } \\
\hline Wheeze & $104 / 730$ & 14 & 13 & 13 & 14 \\
\hline Inhaled steroid use & $109 / 722$ & 15 & 15 & $12^{* *}$ & 16 \\
\hline Doctor's diagnosis of asthma & $55 / 700$ & 8 & 8 & $6^{* *}$ & 9 \\
\hline
\end{tabular}

For each variable, children with and without available data were compared. Significance of differences was tested using a $\chi^{2}$ test.

${ }^{*} \mathrm{p}<0.05$; ${ }^{* *} \mathrm{p}<0.01$.

†Positive if mother reported smoking at least 4 weeks after estimated date of conception. $¥$ Smoking in the child's house more than once a week.

SIn period without a cold, flu or chest infection.

-Defined as a parental report of a doctor's diagnosis of asthma ever, in combination with parental report of symptoms in the past 12 months.

$\mathrm{FE}_{\mathrm{NO}}$, fraction of exhaled nitric oxide; IgE, immunoglobulin $\mathrm{E}$; Rint, interrupter resistance.
Table 2 Variables used to predict asthma symptoms

\begin{tabular}{lll}
\hline Clinical symptoms $(\mathbf{n}=\mathbf{8 4 8})$ & $\mathbf{n} / \mathbf{N}$ & $\mathbf{( \% )}$ \\
\hline $\begin{array}{l}\text { Allergic mother } \\
\text { Wheezing in fourth year of life }\end{array}$ & $567 / 848$ & $(67)$ \\
$\quad$ Infrequent $(1-3$ times/year) & $179 / 848$ & $(21)$ \\
$\quad$ Frequent ( $>3$ times/year) & $64 / 848$ & $(8)$ \\
Doctor's diagnosis of eczema & $388 / 848$ & $(46)$ \\
& & \\
Objective tests & Median (range) & IQR \\
FE $_{\mathrm{No}}$ in ppb ( $\left.\mathrm{n}=306\right)$ & $9.05(2.40-45.9)$ & 6.30 \\
${ }^{10}$ log-transformed $\mathrm{FE}$ & $0.96(0.38-1.66)$ & 0.29 \\
Rint in $\mathrm{kPa} / \mathrm{l}(\mathrm{n}=482)$ & $0.93(0.14-1.99)$ & 0.32 \\
& $\mathrm{n} / \mathrm{N}$ & $(\%)$ \\
Positive specific lgE & $102 / 380$ & $(27)$ \\
\hline
\end{tabular}

$\mathrm{FE}_{\mathrm{NO}}$, fraction of exhaled nitric oxide; lgE, immunoglobulin $\mathrm{E} ;$ Rint, interrupter resistance.

\section{Predictive value of $\mathrm{FE}_{\mathrm{NO}}$}

A higher $\mathrm{FE}_{\mathrm{NO}}$ at 4 years was associated with significantly more wheezing and steroid use between the ages of 5 and 8 years. The association remained more or less stable over the 4 year followup period, with an OR per IOR increase in ${ }^{10} \log \left(\mathrm{FE}_{\mathrm{NO}}\right)$ on 'wheezing' at 8 years of 2.1 (95\% CI 1.3 to 3.3, figure 2). A significant association with doctor's diagnosis of asthma was present only at age 7 . Inclusion of three variables for clinical history in the model had very little effect on the ORs: $\mathrm{FE}_{\mathrm{NO}}$ remained significantly associated with later symptoms, independent of clinical history. Multiple imputed data analyses produced similar associations (online supplement). Fifty-one children used steroids at the age of 4 , which may have influenced $\mathrm{FE}_{\mathrm{NO}}$ measurement. In a sensitivity analysis, exclusion of these children from the analysis led to slightly stronger associations with the outcomes 'doctor's diagnosis of asthma' and 'steroid use'. A charcoal NO scrubber was used while collecting exhaled air to eliminate an influence of ambient $\mathrm{NO}$ on $\mathrm{FE}_{\mathrm{NO}}$ measurements, but some association between $\mathrm{FE}_{\mathrm{NO}}$ and ambient air $\mathrm{NO}$ remained. Adjustment of our models for ambient NO did not change our results.

\section{Predictive value of Rint}

Rint values at age 4 were associated with symptoms at age 5 and 6. The association decreased after the age of 6 and was no longer significant at 8 years (figure 3). Adjustment for clinical history further decreased the association between Rint and all outcomes. The adjusted OR per IOR increase in Rint for wheezing at 8 years was 1.1 (95\% CI 0.7 to 1.6). Multiple imputed analyses did not change this (online supplement).

\section{Predictive value of specific $\lg \mathrm{E}$}

A positive specific IgE to any airborne allergen had a strong association with later symptoms (figure 4). The association remained stable over the 4 year follow-up. At age 8 the OR for 'wheezing' was 6.6 (95\% CI 3.5 to 12.7). When clinical history was taken into account the ORs decreased considerably, but the associations remained strongly significant for all outcomes (OR 4.3 (95\% CI 2.1 to 9.1) for wheezing at 8 years). ORs for specific IgE decreased considerably on all outcomes in the multiple imputed analysis. Since such analyses are less likely to be influenced by selection bias, these estimates are probably more reliable. In the imputed analyses, specific IgE remained the strongest predictor of later symptoms, even when clinical history was taken into account.

\section{Combination of clinical history, $\mathrm{FE}_{\mathrm{No}}$ and specific $\lg \mathrm{E}$}

These results imply that both $\mathrm{FE}_{\mathrm{NO}}$ and specific IgE, independent of clinical history at 4 , significantly improve the prediction of 


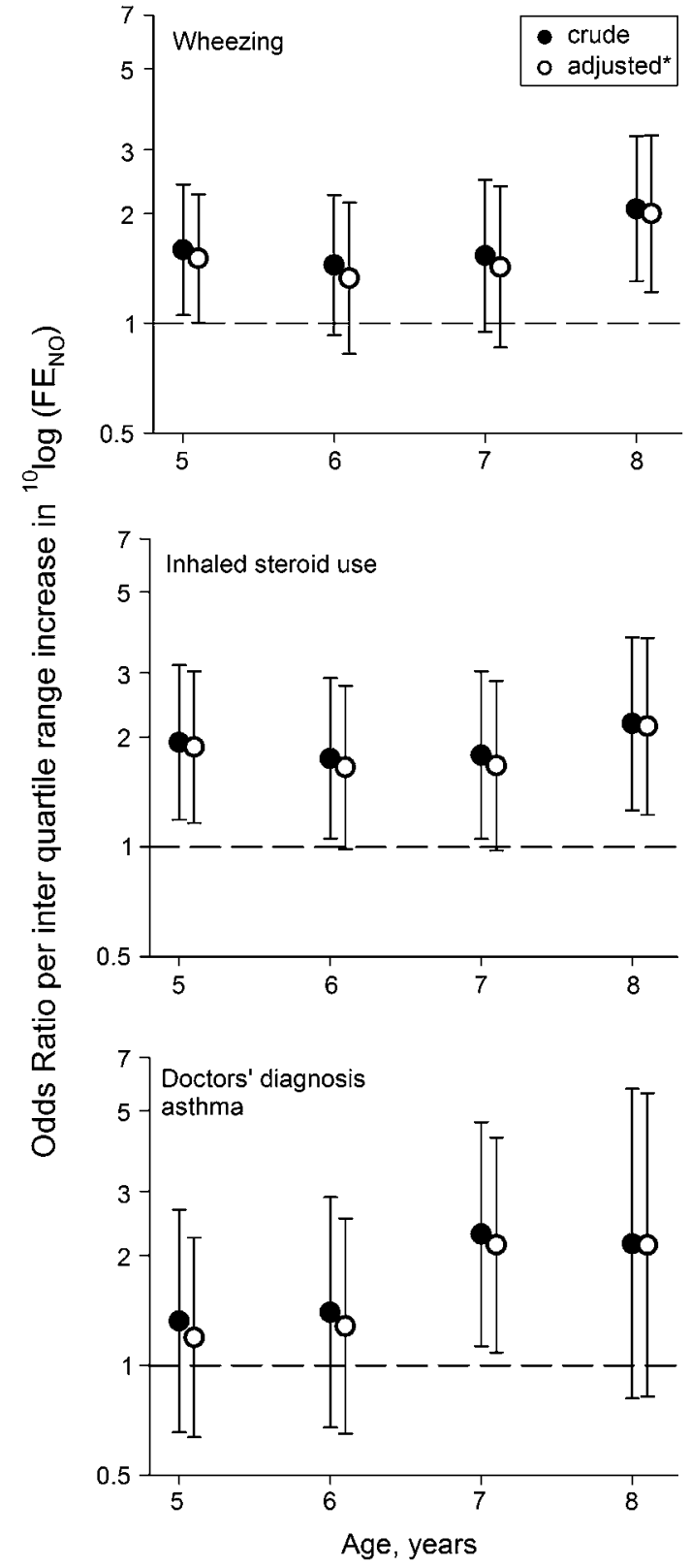

Figure 2 Predictive value of $\mathrm{FE}_{\mathrm{NO}}$ (fraction of exhaled nitric oxide) measured at 4 years on all outcomes at $5-8$ years. Filled circles are crude $\mathrm{ORs}$ for $\mathrm{FE}_{\mathrm{NO}}$ (per IQR increase in ${ }^{10} \log \left(\mathrm{FE}_{\mathrm{NO}}\right)$ ). ${ }^{*}$ Open circles are adjusted for clinical history (allergic mother/doctor's diagnosis of eczema/wheezing at age 4).

asthma symptoms up to the age of 8 years. The question remains of whether $\mathrm{FE}_{\mathrm{NO}}$ still has an added value, when clinical history and specific IgE are already known. We investigated this in a combined model which included $\mathrm{FE}_{\mathrm{NO}}$, specific IgE and clinical history. Complete data on all variables were available from 185 children; the eligible population comprised 848 children. Analyses on the outcome 'wheezing' at age 8 were performed in both populations (table 3). Estimates for $\mathrm{FE}_{\mathrm{NO}}$ and specific IgE were constant in both analyses. The level of significance increased in the multiple imputed analysis, but even in the complete case analysis $(n=185) \mathrm{FE}_{\mathrm{NO}}$ remained borderline significant (table 3 ). Importantly, we found no interaction between $\mathrm{FE}_{\mathrm{NO}}$ and either 'specific IgE' or 'allergic mother'. To visualise the clinical implications of our findings, the predicted probability of wheezing is plotted against $\mathrm{FE}_{\mathrm{NO}}$ values measured at 4 years (figure 5).

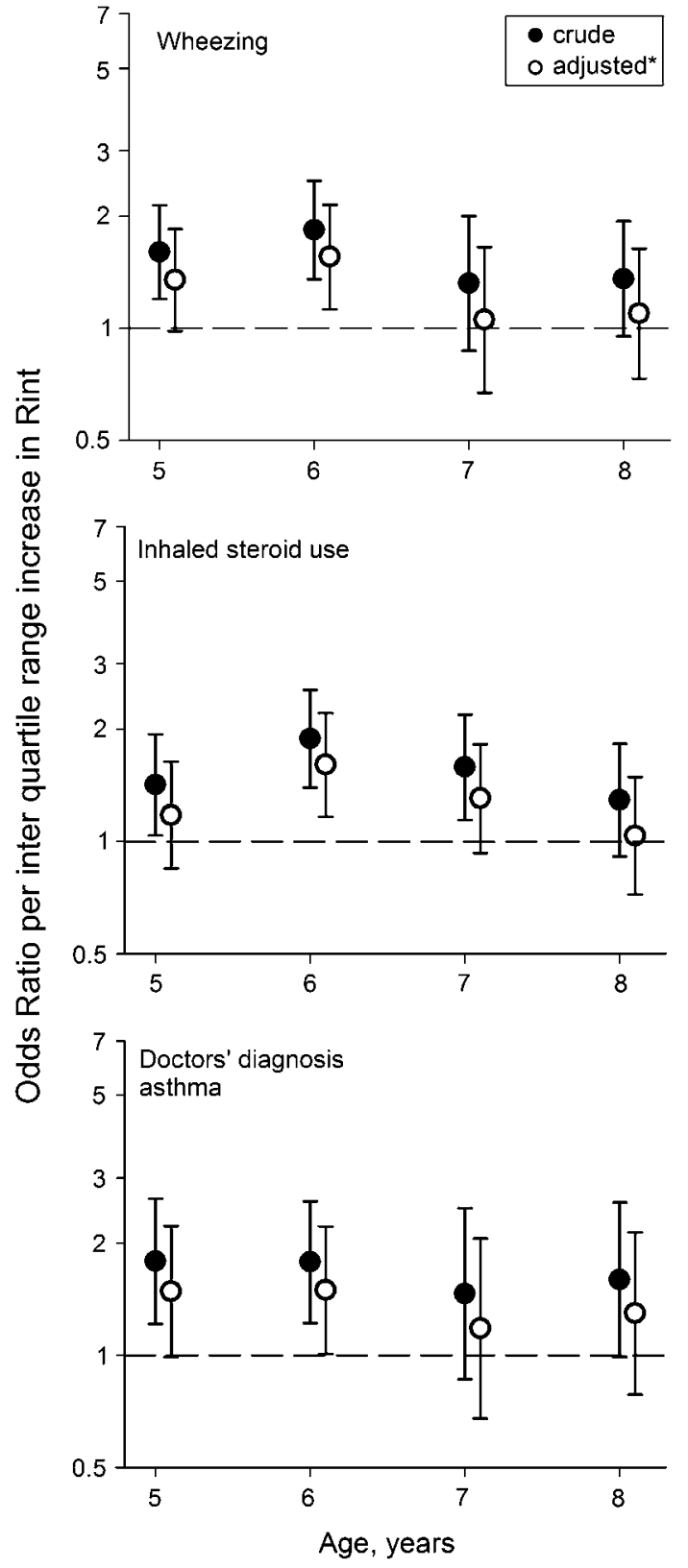

Figure 3 Predictive value of Rint (interrupter resistance) measured at 4 years on all outcomes at $5-8$ years. Filled circles are crude ORs for Rint (per IQR increase). ${ }^{*}$ Open circles are adjusted for clinical history (allergic mother/doctor's diagnosis of eczema/wheezing at age 4).

Different lines represent children with different subsets of risk factors. When all risk factors are absent, $\mathrm{FE}_{\mathrm{NO}}$ appears to be of limited clinical value, because the post-test probability remains low even at higher $\mathrm{FE}_{\mathrm{NO}}$ values. However, in children with an intermediate or high pretest probability of later wheezing, an $\mathrm{FE}_{\mathrm{NO}}$ test at the age of 4 could change the post-test probability to a degree that would be relevant in clinical practice. For example, in children with an allergic mother, eczema and specific IgE, but with infrequent wheezing at 4 (thick dashed line, figure 5), risk of asthma symptoms at 8 ranged from $25 \%$ to $70 \%$ depending on $\mathrm{FE}_{\mathrm{NO}}$ measured at 4 years.

\section{DISCUSSION}

We show that in preschool children with symptoms suggestive of asthma, measurement of $\mathrm{FE}_{\mathrm{NO}}$ and specific IgE could predict 


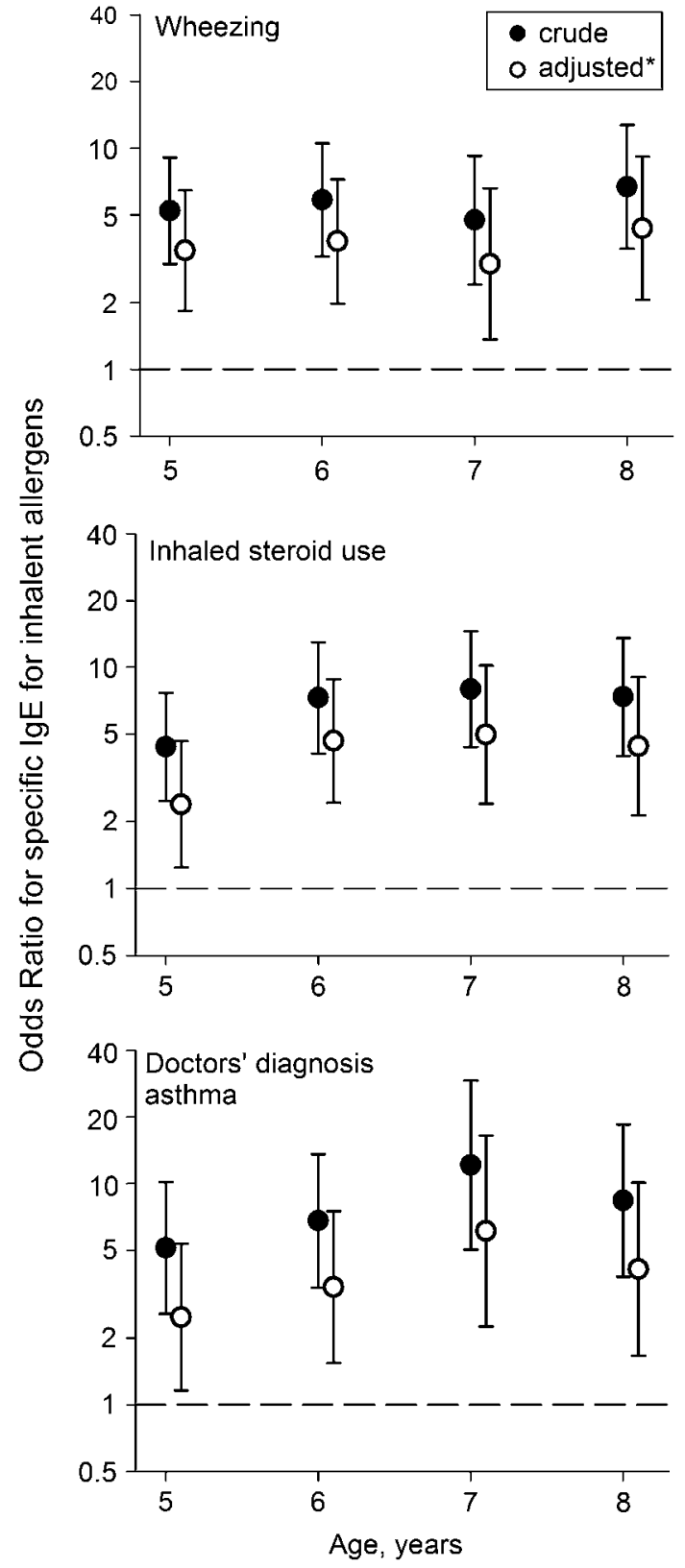

Figure 4 Predictive value of specific IgE (immunoglobulin E) measured at 4 years on all outcomes at $5-8$ years. Filled circles are crude ORs for specific IgE. * Open circles are adjusted for clinical history (allergic mother/doctor's diagnosis of eczema/wheezing at age 4).

later asthma symptoms, up to the age of 8 . Both tests had an added predictive value, independent of each other and of clinical history.

Several studies investigating the association between $\mathrm{FE}_{\mathrm{NO}}$ and airway symptoms in children reported a higher $\mathrm{FE}_{\mathrm{NO}}$ in children with wheezing and asthma. ${ }^{6} 7911$ Malmberg and colleagues even reported an $86 \%$ sensitivity and $92 \%$ specificity of $\mathrm{FE}_{\mathrm{NO}}$ to diagnose asthma, clearly superior to conventional bronchoprovocation testing and spirometry. ${ }^{9}$ Importantly, these studies selected children already known to have asthma, and healthy controls. Such a case-control design is likely to cause selection bias, with overestimation of a test's diagnostic performance. ${ }^{31}$ In unselected groups of schoolchildren, a much lower diagnostic performance of $\mathrm{FE}_{\mathrm{NO}}$ was reported. ${ }^{12}{ }^{32}$ Age is important when comparing different studies, due to heterogeneous respiratory disorders and changing $\mathrm{FE}_{\mathrm{NO}}$ during
Table 3 Predictive value of $\mathrm{FE}_{\mathrm{NO}}$ and specific IgE on 'wheezing' (with mutual adjustment and adjustment for clinical history) ${ }^{*}$

\begin{tabular}{|c|c|c|}
\hline & $\mathrm{FE}_{\mathrm{No}} \dagger$ & Specific IgE \\
\hline $\begin{array}{l}\mathrm{n}=185 \\
\mathrm{FE}_{\mathrm{NO}} \text { and } \lg \mathrm{E} \\
\text { both available }\end{array}$ & $\begin{array}{l}1.65 \\
(95 \% \mathrm{Cl} 0.94 \text { to } 2.89) \mathrm{p}=0.078\end{array}$ & $\begin{array}{l}2.86 \\
(95 \% \mathrm{Cl} 1.38 \text { to } 5.91) \mathrm{p}=0.005\end{array}$ \\
\hline $\begin{array}{l}\mathrm{n}=848 \\
\text { Total eligible } \\
\text { population }\end{array}$ & $\begin{array}{l}1.57 \\
(95 \% \mathrm{Cl} 1.10 \text { to } 2.23) \mathrm{p}=0.016\end{array}$ & $\begin{array}{l}2.78 \\
(95 \% \mathrm{Cl} 1.90 \text { to } 4.07) \mathrm{p}<0.001\end{array}$ \\
\hline \multicolumn{3}{|c|}{$\begin{array}{l}\mathrm{ORs}(95 \% \mathrm{CI}) \text { of } \mathrm{FE}_{\mathrm{NO}} \text { and specific IgE on the outcome of 'wheezing', using complete case } \\
\text { data }(\mathrm{n}=185) \text { and multiple imputed data }(\mathrm{n}=848) \text {. } \\
{ }^{*} \mathrm{ORs} \text { for } \mathrm{FE}_{\mathrm{NO}} \text { and specific IgE were mutually adjusted for each other, and for three } \\
\text { variables on clinical history (allergic mother/doctor's diagnosis of eczema/wheezing } \\
\text { at age 4). } \\
\text { †ORs for } \mathrm{FE}_{\mathrm{NO}} \text { are calculated per IQR increase in }{ }^{10} \text { log-transformed } \mathrm{FE}_{\mathrm{NO}} \text {. } \\
\mathrm{FE}_{\mathrm{NO}} \text {, fraction of exhaled nitric oxide; IgE, immunoglobulin } \mathrm{E} \text {; Rint, interrupter resistance. }\end{array}$} \\
\hline
\end{tabular}

childhood. $^{33} 34$ In children aged 4 years, higher $\mathrm{FE}_{\mathrm{NO}}$ values were measured in recurrent wheezers and in children with doctordiagnosed asthma, with considerable overlap. ${ }^{8} 10$ Moeller et al showed that $\mathrm{FE}_{\mathrm{NO}}$ could be used to distinguish between different phenotypes of preschool wheezers, based on their clinical history up to the age of 4 . However, FeNO will only have a clinical benefit if it offers additional information compared with clinical history. ${ }^{13}$ Previous studies were cross-sectional, and very little is known about the predictive value of $\mathrm{FE}_{\mathrm{NO}}$ on later asthma in preschool children. We performed a 4 year follow-up and took the child's clinical history into account to assess the true additional predictive value of $\mathrm{FE}_{\mathrm{NO}}$ for later asthma. This reflects the clinical setting in which $\mathrm{FE}_{\mathrm{NO}}$ would be used. Our prospective analysis shows that $\mathrm{FE}_{\mathrm{NO}}$ measured at 4 years indeed improved prediction of asthma until the age of 8 years.

Cross-sectional studies have reported higher Rint in those with asthma compared with controls, with considerable overlap. ${ }^{14} 1535$ Previous analysis of our own data at age 4 showed a higher Rint in persistent wheezers, compared with

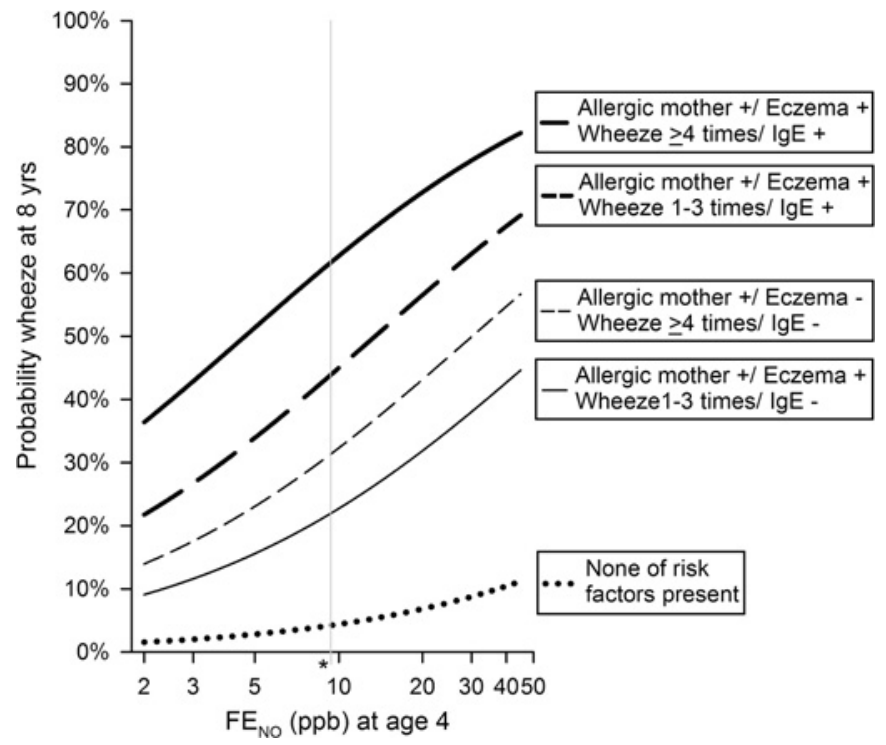

Figure 5 Predicted probability of 'asthma symptoms' depending on $\mathrm{FE}_{\mathrm{NO}}$ (fraction of exhaled nitric oxide) at 4 years. Predicted probability for 'wheezing' at age 8 is modelled for $\mathrm{FE}_{\mathrm{NO}}$ values (unit: parts per billion) measured at age 4, adjusted for specific immunoglobulin $E(\lg E)$, allergic mother, doctor's diagnosis of eczema and wheezing frequency at age 4. Different lines represent children with different subsets of risk factors. The horizontal axis is in log scale. * The vertical grey line represents the geometrical mean $\mathrm{FE}_{\mathrm{NO}}$ in the study population and can be used to determine the pretest probability of wheeze at 8 for individual children. 
children who never or transiently wheezed. ${ }^{25}$ The only prospective study on the predictive value of Rint measurements was performed in a cohort of 110 children diagnosed with asthma (aged $2-5$ years) and found no association between Rint and asthma medication after 3 years follow-up. ${ }^{36}$ Our study recruited children from a population-based cohort, based on reported respiratory symptoms, and results were similar: Rint at age 4 did not discriminate between children with or without symptoms at 8 years. Although Rint was associated with symptoms up to 2 years after measurement, it was not useful in the long-term management of individual children. Thirty-nine children $(7 \%)$ were excluded because bronchodilators were used within $24 \mathrm{~h}$ prior to Rint measurement. When these children were included, the predictive power of Rint was even smaller. Nonetheless, selective exclusion of this group of high risk children may have decreased the power to detect an association of Rint with later symptoms.

Prospective studies showed that children with positive specific IgE for inhalant allergens were more likely to develop wheeze ${ }^{19}$ and asthma ${ }^{18}$ in childhood. Even when information from patient history is considered, specific IgE improved prediction of later asthma. ${ }^{1720}$ Our results show that the predictive value of specific IgE measured at 4 years remains high until the age of 8 . Importantly, our data allowed us to investigate the independent added value of specific $\operatorname{IgE}$ and $\mathrm{FE}_{\mathrm{NO}}$ measurements at 4. Several authors reported raised $\mathrm{FE}_{\mathrm{NO}}$ levels in children with atopy rather than asthma. ${ }^{32}{ }^{37}$ Consequently, it has been proposed that any predictive value of $\mathrm{FE}_{\mathrm{NO}}$ for asthma might be explained by its correlation with specific IgE. ${ }^{38}$ Our combined analysis shows that even though $\mathrm{FE}_{\mathrm{NO}}$ and specific IgE are correlated, they both independently contributed to the prediction of later asthma symptoms.

Major strengths of this study are its longitudinal design and large sample size. In the selection of the eligible population and the statistical analysis we aimed to mimic the clinical setting. This enabled us to estimate the true added value of the tests and hence their clinical relevance.

Selection bias could have resulted from incomplete data. However, we found that children with complete data did not differ from those with incomplete data. Furthermore, a multiple imputed analysis including all eligible children led to similar results and did not change any of our conclusions (online data supplement). Secondly, the PIAMA study is an unselected birth cohort, but due to over-representation of children with an allergic mother in the medical examination at 4, our eligible population included more children with an allergic mother. If the predictive value of $\mathrm{FE}_{\mathrm{NO}}$, Rint or specific IgE differs between children with and without an allergic mother, this would limit the generalisability of our findings. We consider this unlikely since there was no interaction between any of the tests and the variable 'allergic mother'. Hence, our findings may be generalisable to all children in the general population with asthma symptoms at 3-4 years. Although steroid use is well known to decrease $\mathrm{FE}_{\mathrm{NO}}$, we decided to include 51 (17\%) children who used inhaled corticosteroids at age 4 . This may have led to some underestimation of the predictive power of $\mathrm{FE}_{\mathrm{NO}}$, but we preferred this over selective exclusion of 51 high risk children. Finally, in order not to overestimate the added prognostic value of $\mathrm{FE}_{\mathrm{NO}}$, Rint and specific $\operatorname{IgE}$ over a clinical history we tested which variables for clinical history were the best prognostic indicators for later symptoms, and added the three variables with the strongest association in our multivariable analysis. ${ }^{39}$ Including a variable for wheezing phenotype (multitrigger wheeze/viral induced wheeze/no wheeze) in our models did not decrease the predictive ability of any of the three investigated tests.

Do our findings have clinical relevance? In the management of wheezing preschool children a first step will always be to take a full medical history. Secondly, a specific IgE test has the highest predictive value for symptom persistence. $\mathrm{FE}_{\mathrm{NO}}$ measurement as a next step can significantly improve prediction of later asthma symptoms, especially in children with an intermediate pretest risk.

In conclusion, we demonstrated that in preschool children with symptoms suggestive of asthma, both $\mathrm{FE}_{\mathrm{NO}}$ and specific $\mathrm{IgE}$ at age 4 predicted asthma symptoms until the age of 8 years independently, and independent of clinical history. Specific IgE had the highest predictive value; the added value of $\mathrm{FE}_{\mathrm{NO}}$ was limited. Nevertheless, in children with an intermediate or high risk, $\mathrm{FE}_{\mathrm{NO}}$ substantially changed the risk of later wheezing and asthma to a degree that may be relevant in clinical practice.

Acknowledgements The authors gratefully acknowledge Dr Maarten Schipper for providing valuable discussion and suggestions on the data analysis.

Funding The Netherlands Organisation for Health Research and Development; the Netherlands Organisation for Scientific Research; the Netherlands Asthma Fund; the Netherlands Ministry of Spatial Planning, Housing, and the Environment; and the Netherlands Ministry of Health, Welfare and Sport. The salary of DC was paid by a 'Toptalent' grant from the Netherlands Organisation for Scientific Research (NWO). None of the funding sources had a role in either the study design, data collection, analyses, interpretation of the data, writing of the report or decision to submit this paper for publication.

\section{Competing interests None.}

Ethics approval The study protocol was approved by the medical ethics committees of the participating university hospitals: ErasmusMC, University Medical Centre Rotterdam, University Medical Centre Groningen, University Medical Centre Utrecht.

Contributors All the authors contributed sufficiently to study design, data collection, data analysis and writing of the paper to meet the criteria for authorship.

Provenance and peer review Not commissioned; externally peer reviewed.

\section{REFERENCES}

1. Kuehni CE, Davis A, Brooke AM, et al. Are all wheezing disorders in very young (preschool) children increasing in prevalence? Lancet 2001;357:1821-5.

2. The Global Strategy for Asthma Management and Prevention, Global Initiative for Asthma (GINA) 2008. http://www.ginasthma.org (accessed 20 Mar 2009).

3. Kanengiser S, Dozor AJ. Forced expiratory maneuvers in children aged 3 to 5 years. Pediatr Pulmonol 1994:18:144-9.

4. Jatakanon A, Lim S, Kharitonov SA, et al. Correlation between exhaled nitric oxide, sputum eosinophils, and methacholine responsiveness in patients with mild asthma. Thorax 1998:53:91-5

5. Piacentini GL, Bodini A, Costella $S$, et al. Exhaled nitric oxide and sputum eosinophil markers of inflammation in asthmatic children. Eur Respir J 1999;13:1386-90.

6. Avital A, Uwyyed K, Berkman N, et al. Exhaled nitric oxide and asthma in young children. Pediatr Pulmonol 2001;32:308-13.

7. Baraldi E, Dario C, Ongaro R, et al. Exhaled nitric oxide concentrations during treatment of wheezing exacerbation in infants and young children. Am J Respir Crit Care Med 1999;159:1284-8.

8. Brussee JE, Smit HA, Kerkhof M, et al. Exhaled nitric oxide in 4-year-old children: relationship with asthma and atopy. Eur Respir J 2005;25:455-61.

9. Malmberg LP, Pelkonen AS, Haahtela T, et al. Exhaled nitric oxide rather than lung function distinguishes preschool children with probable asthma. Thorax 2003:58:494-9.

10. Meyts I, Proesmans M, Van Gerven V, et al. Tidal off-line exhaled nitric oxide measurements in a pre-school population. Eur J Pediatr 2003;162:506-10.

11. Narang I, Ersu R, Wilson NM, et al. Nitric oxide in chronic airway inflammation in children: diagnostic use and pathophysiological significance. Thorax 2002:57:586-9.

12. Thomas PS, Gibson PG, Wang $H$, et al. The relationship of exhaled nitric oxide to airway inflammation and responsiveness in children. J Asthma 2005;42:291-5.

13. Moeller A, Diefenbacher C, Lehmann A, et al. Exhaled nitric oxide distinguishes between subgroups of preschool children with respiratory symptoms. J Allergy Clin Immunol 2008;121:705-9.

14. Beydon N, Pin I, Matran R, et al. Pulmonary function tests in preschool children with asthma. Am J Respir Crit Care Med 2003;168:640-4.

15. McKenzie SA, Bridge PD, Healy MJ. Airway resistance and atopy in preschool children with wheeze and cough. Eur Respir J 2000;15:833-8. 
16. Merkus PJ, Mijnsbergen JY, Hop WC, et al. Interrupter resistance in preschool children: measurement characteristics and reference values. Am J Respir Crit Care Med 2001;163:1350-5.

17. Eysink PE, ter Riet G, Aalberse RC, et al. Accuracy of specific lgE in the prediction of asthma: development of a scoring formula for general practice. $\mathrm{Br} J$ Gen Pract 2005;55:125-31.

18. Kotaniemi-Syrjanen A, Reijonen TM, Romppanen J, et al. Allergen-specific immunoglobulin $\mathrm{E}$ antibodies in wheezing infants: the risk for asthma in later childhood. Pediatrics 2003:111:e255-61.

19. Matricardi PM, Illi S, Gruber C, et al. Wheezing in childhood: incidence, longitudinal patterns and factors predicting persistence. Eur Respir J 2008;32:585-92.

20. Wever-Hess J, Kouwenberg JM, Duiverman EJ, et al. Prognostic characteristics of asthma diagnosis in early childhood in clinical practice. Acta Paediatr 1999;88:827-34.

21. Brunekreef B, Smit J, de Jongste J, et al. The prevention and incidence of asthma and mite allergy (PIAMA) birth cohort study: design and first results. Pediatr Allergy Immunol 2002:13 (Suppl 15):55-60.

22. Lakwijk N, Van Strien RT, Doekes G, et al. Validation of a screening questionnaire for atopy with serum IgE tests in a population of pregnant Dutch women. Clin Exp Allergy 1998;28:454-8.

23. Asher MI, Keil U, Anderson HR, et al. International Study of Asthma and Allergies in Childhood (ISAAC): rationale and methods. Eur Respir J 1995;8:483-91.

24. Baraldi E, de Jongste JC. Measurement of exhaled nitric oxide in children, 2001. Eur Respir J 2002;20:223-37.

25. Brussee JE, Smit HA, Koopman LP, et al. Interrupter resistance and wheezing phenotypes at 4 years of age. Am J Respir Crit Care Med 2004;169:209-13.

26. Caudri D, Wijga A, A Schipper CM, et al. Predicting the long-term prognosis of children with symptoms suggestive of asthma at preschool age. J Allergy Clin Immunol 2009;124:903-10.

27. van Buuren S, Boshuizen HC, Knook DL. Multiple imputation of missing blood pressure covariates in survival analysis. Stat Med 1999;18:681-94.
28. van der Heijden GJ, Donders AR, Stijnen $T$, et al. Imputation of missing values is superior to complete case analysis and the missing-indicator method in multivariable diagnostic research: a clinical example. J Clin Epidemiol 2006:59:1102-9.

29. Van Buuren S, Oudshoorn CGM. Mice: multivariate imputation by chained equations. R package version 1.16; 2007. http://web.inter.nl.net/users/S.van.Buuren/ $\mathrm{mi} / \mathrm{hmtl} / \mathrm{mice} . \mathrm{htm}$ (accessed 10 Mar 2008).

30. R Development Core Team. $R$ : a language and environment for statistical computing. Vienna, Austria: R Foundation for Statistical Computing, 2007. http://www.R-project.org (accessed 23 Mar 2007)

31. Lijmer JG, Mol BW, Heisterkamp S, et al. Empirical evidence of design-related bias in studies of diagnostic tests. JAMA 1999;282:1061-6.

32. Prasad A, Langford B, Stradling JR, et al. Exhaled nitric oxide as a screening tool for asthma in school children. Respir Med 2006;100:167-73.

33. Martinez FD, Wright AL, Taussig LM, et al. Asthma and wheezing in the first six years of life. The Group Health Medical Associates. N Engl J Med 1995;332:133-8.

34. Avital A, Uwyyed K, Berkman N, et al. Exhaled nitric oxide is age-dependent in asthma. Pediatr Pulmonol 2003;36:433-8.

35. Nielsen KG, Bisgaard $H$. Discriminative capacity of bronchodilator response measured with three different lung function techniques in asthmatic and healthy children aged 2 to 5 years. Am J Respir Crit Care Med 2001;164:554-9.

36. Klug B, Bisgaard H. Lung function and short-term outcome in young asthmatic children. Eur Respir J 1999:14:1185-9.

37. Jouaville LF, Annesi-Maesano I, Nguyen LT, et al. Interrelationships among asthma atopy, rhinitis and exhaled nitric oxide in a population-based sample of children. Clin Exp Allergy 2003;33:1506-11.

38. Franklin PJ, Stick SM. The value of FeNO measurement in asthma management: the motion against FeNO to help manage childhood asthma-reality bites. Paediatr Respir Rev 2008;9:122-6.

39. Peduzzi P, Concato J, Kemper $\mathbf{E}$, et al. A simulation study of the number of events per variable in logistic regression analysis. J Clin Epidemiol 1996:49:1373-9.

\section{Lung alert}

\section{Maternal vitamin A supplementation improves lung function in offspring}

Vitamin A has an important role in fetal lung development. This study tested the hypothesis that maternal vitamin A deficiency could have a long-term adverse effect on the lung function of offspring, quantified by reduced forced expiratory volume in $1 \mathrm{~s}\left(\mathrm{FEV}_{1}\right)$ and forced vital capacity (FVC).

The participants were a cohort of rural Nepali children, aged between 9 and 13 years, whose mothers had taken part in an original study aimed to determine the effects of vitamin A, $\beta$-carotene or placebo supplementation throughout pregnancy on maternal death rates.

Over a 2 year period spirometric data were collected from 1371 children ( $83 \%$ of those eligible for participation after the original study). Results demonstrated normally distributed $\mathrm{FEV}_{1}$ and FVC volumes, with means of 1.54 and 1.74 litres, respectively. Compared with the placebo group, the $\mathrm{FEV}_{1}$ was $46 \mathrm{ml}$ higher in the children whose mothers had received vitamin A supplementation throughout pregnancy, and $14 \mathrm{ml}$ higher in the $\beta$-carotene group than the placebo group. Even after adjustment for confounders such as age, height and sex, a similar comparison was made for FVC. Compared with the placebo group the FVC was $46 \mathrm{ml}$ higher in the vitamin $\mathrm{A}$ group and $17 \mathrm{ml}$ higher in the $\beta$-carotene group.

The study concludes that repletion of vitamin $A$ and, to a lesser degree, $\beta$-carotene during pregnancy improves lung function, potentially providing long-term public health benefits.

Checkley W, West KP, Wise RA, et al. Maternal vitamin A supplementation and lung function in offspring. N Engl J Med 2010;362:1784-94.

\section{Dardis}

Correspondence to C Dardis, Leeds General Infirmary, Leeds, UK; cdardis@doctors.org.uk 